\title{
Mini-Invasive Collagen Sling in the Treatment of Urinary Incontinence Due To Sphincteric Incompetence
}

\author{
Seppo Taskinen, Riitta Fagerholm, Risto Rintala
}

Hospital for Children and Adolescents, Helsinki University, Helsinki, Finland

\begin{abstract}
Objective: To assess the technical feasibility of mini-invasive sling procedure and present preliminary results in the treatment of urinary incontinence due to sphincteric insufficiency.

Materials and Methods: Thirteen patients ( 6 males, 7 females, 8 with myelomeningocele, 1 with tethered spinal cord, 3 with bladder exstrophy, 1 with epispadias) underwent sling procedure with porcine dermis acellular collagen matrix (Pelvilace ${ }^{\mathrm{TM}}$, Bard medical, UK). The median age was 15.5 (range 8.9-27.5) years. A suprapubic catheter was inserted for the measurement of leak point pressure during the operation. In females vaginal and in males perineal incision was used for sling insertion. The sling was introduced under cystoscopic control. The sling was not fixed with sutures. The outcomes were reviewed at 1,6 and 12 month after the operation.

Results: The median leak point pressure increased from 21.5 (range 5-25) $\mathrm{cm} \mathrm{H} 2 \mathrm{O}$ to 85 (range 70-100) $\mathrm{cm} \mathrm{H2O}$. At 1 month 8 and at 6 months 3 out of 13 patients were dry. At 12 months, none out of 11 patients was completely dry. However, at 12 months some improvement in incontinence was detected in 9 out of 11 patients. Two patients had primary failures. One patient got sling erosion to urethra after a tightening attempt. In one patient detrusor overactivity increased after the sling procedure.

Conclusions: Pelvilace ${ }^{\mathrm{TM}}$ sling is safe and easy to introduce in both males and females if pelvic floor anatomy is normal. Although immediate results were promising in neuropathic incontinence, the results seem to deteriorate to unacceptable low level already during the first year. In exstrophy patients the results are generally poor.
\end{abstract}

Key words: urinary incontinence; children; neuropathic bladder; suburethral sling

Int Braz. J Urol. 2007; 33: 395-406

\section{INTRODUCTION}

Mini-invasive tension-free vaginal tapes (TVT) have become popular in the treatment of female stress urinary incontinence (1). Unlike healthy females, the children with stress incontinence usually do not have functional sphincter mechanism and, therefore, the treatment is very challenging. The typi- cal cases of sphincteric insufficiency in children are neuropathic problems such as myelomeningocele (MMC) and congenital anomalies such as bladder exstrophy (2). Fascial slings with tension have been used in these conditions with success rates of around $70 \%$ (2,3). Mini-invasive TVT techniques have not gained popularity in pediatric urology. In children with non-functioning sphincter mechanism, some tension 
is needed in the sling. With synthetic materials the risk of erosion probably increases with tension. In the present study we examined the feasibility of mini-invasive technique with biological material to manage sphincteric incompetence in children and young adults. Short term outcomes as well as the technique of the sling procedure are described in patients who had neuropathic or congenital causes of incontinence.

\section{MATERIALS AND METHODS}

Thirteen patients with refractory incontinence due to sphincteric incompetence underwent porcine dermis acellular collagen matrix sling (Pelvilace ${ }^{\mathrm{TM}}$, Bard medical, UK) insertion from August 2004 to June 2006. The patients were considered to have a low-pressure bladder although anticholinergic medication was started in 8 of them preoperatively. The study was prospective and observational. The median age of the patients was 15.5 (range 8.9-27.5) years. There were 6 males (3 with MMC and 3 with bladder exstrophy) and 7 females ( 5 with MMC, 1 with tethered spinal cord, and 1 with epispadias). Ten had previously had unsuccessful periurethral injections with dextranomer/hyaluronic acid copolymer (Deflux R). All the patients used clean intermittent catheterizations (CIC). Five patients had undergone bladder augmentation because of urinary incontinence; one of those had augmentation concomitantly with the sling procedure.

Suprapubic bladder catheter was inserted for the measurement of leak point pressures. Pressure was generated to full bladder during general anesthesia with manual compression on the lower abdomen. There was no muscle relaxation at the time of leak point measurements. In females a vaginal and in males a perineal incision was used. The proper location of the sling was determined with the aid of cystoscopy. Urethral wall was approached in the area of mid urethra in females and distal to the colliculus seminalis in males. Insertion needles were introduced on both sides of urethra and brought out above pubic symphysis. After cystoscopic examination the sling was pulled in its place with insertion needles. The sling was tightened so that the leak point pressure increased to a minimum of $70 \mathrm{~cm} \mathrm{H} 2 \mathrm{O}$. One male with bladder exstrophy required two slings before the leak point pressure increased. The sling was cut at the skin level above the symphysis without suture fixation. In males the perineal incision was closed in two layers and in girls the vaginal incision was closed in one layer using absorbable sutures. CIC was started two days after operation and the suprapubic catheter was removed if no postoperative problems were noted.

The functional outcome in terms of incidence of wet pads was analyzed at 1 and 6 month in all 13 and at 12 months postoperatively in 11 patients. The patients were asked to change dry pads after every catheterization during the last two weeks. Because all patients made catheterization five times a day, 70 pads were used during two weeks. In addition to the number of wet pads the patients were asked to register if the pads were really wet (major leaks) or damp (minor leaks).

Before the operation all of the patients, except one with total incontinence, had undergone a urodynamic study. Six months after the operation a control study was available in nine patients. Abdominal and bladder pressures were measured with $4 \mathrm{Ch}$ feeding tubes. Subtracted detrusor pressure was measured simultaneously using computerized equipment (Dantec Menuet, Denmark). Bladder filling was performed with a separate $6 \mathrm{Ch}$ feeding tube with the rate of $10 \mathrm{~mL} / \mathrm{min}$. Bladder capacity and maximal pressures during the filling were recorded. Urethral pressure profile was also measured with an empty bladder and maximal closing pressure was recorded. Pre- and postoperative urodynamic results were compared with a paired t-test.

\section{RESULTS}

During the insertion of the sling the median leak point pressure increased from 21.5 (range 5-25) $\mathrm{cm} \mathrm{H} 2 \mathrm{O}$ to 85 (range 70-100) cm H2O. Two males had primary failures. Sling erosion to urethra was detected one month postoperatively in one patient with bladder exstrophy following an attempt to tighten and fix the sling. Cystoscopic forceps ablation of the sling material was attempted unsuccessfully. However, in 
control cystoscopy three months later, no sling material could be detected. In one patient the insertion needle perforated the bladder. The needle position was corrected before the insertion of the sling and there were no adverse late effects. Transurethral catheterization was started after two days in all except three patients. One had a continent stoma and another had undergone concomitant bladder augmentation. One male with exstrophy was not able to do CIC during the first week. One boy with MMC experienced some difficulties in CIC during the first months. During the first month another patient had slight discharge from abdominal incision that ceased with antibiotic treatment. The male patient with simultaneous augmentation and sling procedure had no immediate postoperative problems.

Eight out of 13 patients had achieved total continence one month postoperatively and one had minor leaks (Table-1). One male with bladder exstrophy was totally incontinent as well as another patient with MMC. Another male with bladder exstrophy had polyuria due to diabetes mellitus and he was leaking between most catheterizations. However, he was no more totally incontinent, and remained dry 1-2 hour after CIC. At six months 3 out of 13 evaluated patients were completely dry and six had minor leaks when bladder overfilled. Four had significant amounts of wetting. At 12 months all 11 patients that could be evaluated had incontinence episodes. 5 of them were wet between every CIC. However, 7 out of 11 had mainly minor leaks when the bladder was overfilled. The degree of incontinence in 9 out of the 11 patients was lesser compared to the preoperative situation after one year follow-up.

In urodynamic studies the median pre- and postoperative bladder capacities were 339 (range 237-663) $\mathrm{mL}$ and 507 (range 330-824) $\mathrm{mL}$ respectively ( $\mathrm{p}=0.0186)$. The patient who had the simultaneous augmentation with the sling procedure had 81 $\mathrm{cm} \mathrm{H} 2 \mathrm{O}$ maximal detrusor pressure preoperatively. In the other patients maximal preoperative detrusor pressures were low 14 (range 3-38) $\mathrm{cm} \mathrm{H2O}$. There was a non significant increase in detrusor pressures postoperatively to 21 (range 2-97) $\mathrm{cm} \mathrm{H} 2 \mathrm{O}$ (p = 0.3249 ). However, in one patient the increase in maximal detrusor pressure was significant (from 18 cm $\mathrm{H} 2 \mathrm{O}$ preoperatively to $97 \mathrm{~cm} \mathrm{H} 2 \mathrm{O}$ after the sling procedure). The maximal closing pressures in urethral pressure profile increased significantly from the median preoperative values 22 (range 5-42) $\mathrm{cm} \mathrm{H} 2 \mathrm{O}$ to 38 (range $25-63) \mathrm{cm} \mathrm{H} 2 \mathrm{O}(\mathrm{p}=0.0037)$. In 8 patients anticholinergic medication was started before the sling procedure because of slight detrusor overactivity at the end of filling. In the two patients Botulinum toxin type $\mathrm{A}$ (Botox $\left.{ }^{\circledR}\right)$ injection therapy has been attempted postoperatively. The primary results were promising in both of them. However, the effect subsided after two months in one but the other has had a good effect more than one year.

\section{COMMENTS}

In women sling procedures for urinary incontinence have been introduced about 100 years ago (1). Originally autogenic fascia was used with good success rates and good durability (1). Synthetic materials have been used later to avoid major abdominal incision, but the erosion rates have been quite high ranging from 2 to $23 \%$ (4). Mini-invasive tension free sling techniques have been used in healthy females with good primary success rates. Continence rate after TVT has been $85 \%$ with synthetic material and $89 \%$ with biological material (5). The long-term success with synthetic sling materials has also turned out to be good (6). The complication rates following TVT are low in healthy females (7). Sling suspension with commercially available products has also been successfully used in males after radical prostatectomy (8).

In children insertion of allogenic fascial slings have resulted in urinary continence in $25-78 \%$ patients with a small risk of urethral erosion $(2,3,9,10)$.

Commercial products have been also used in pediatric patients. In a series of 20 children insertion of acellular small intestine submucosal collagen sling in an open operation has been reported to yield complete dryness in $70 \%$ of patients after a mean of 13 months follow-up (11). However, there are no reports of mini-invasive sling techniques in pediatric patients. The reason may be that there is a well-documented erosion risk of foreign material to the urethra especially when tension is applied to the sling. In addition, 
Table 1 - Patients with Pelvilace ${ }^{T M}$ sling procedure and the number of wet pads during last 2 weeks at preoperative period as well as at 1, 6 and 12 months postoperatively. All the patients have clean intermittent catheterizations 5 times a day and used 70 pads during 2 weeks.

\begin{tabular}{|c|c|c|c|c|c|c|}
\hline \multicolumn{7}{|c|}{ Number of Wet Pads / 70 Pads } \\
\hline & $\operatorname{Age}(y)$ & Preop & 1 month & 6 months & 12 months & Bladder Treatment \\
\hline \multicolumn{7}{|l|}{ Male } \\
\hline $\mathrm{MMC}$ & 8.9 & 70 & 0 & 0 & $70 *$ & simultaneous augmentation \\
\hline MMC & 9.3 & 70 & 0 & $70^{*}$ & $26^{*}$ & tolterodine, Botox ${ }^{\circledR}$ \\
\hline MMC & $15.1 * *$ & 70 & 70 & 70 & & oxybutynin \\
\hline Exstrophy & $10.1 * *$ & 70 & 70 & 70 & 70 & \\
\hline Exstrophy & 13.4 & $19 *$ & 0 & $3^{*}$ & & previous augmentation, oxybutynin \\
\hline Exstrophy & 15.5 & 70 & $42 *$ & $42 *$ & 70 & previous augmentation \\
\hline \multicolumn{7}{|l|}{ Female } \\
\hline MMC & 12 & 70 & 0 & $28^{*}$ & $70 *$ & oxybutynin \\
\hline MMC & 15.8 & 70 & 2 & $2^{*}$ & $70 *$ & oxybutynin \\
\hline MMC & 26.2 & 70 & 0 & 0 & $42 *$ & previous augmentation \\
\hline MMC & 27.5 & 28 & 0 & 7 & 3 & oxybutynin, Botox ${ }^{\circledR}$ \\
\hline MMC & 28.9 & 70 & 0 & $40 *$ & $35^{*}$ & previous augmentation \\
\hline Tethered cord & 18.5 & 30 & 14 & 16 & 16 & oxybutynin \\
\hline Epispadias & 15.5 & 70 & 0 & 0 & $35^{*}$ & oxybutynin \\
\hline
\end{tabular}

MMC = myelomeningocele $;=$ minor leaking, especially at full bladder $; *$ = total failure.

the instrumentation of mini-invasive techniques is designed for adult females. In the present series we started to apply mini-invasive technique in adult females, but gradually have lowered the patient age and also began to use the technique in male patients. In the present study the sling was originally applied with a slight tension without fixation sutures. In these patients no erosion was detected. In one patient with primary failure the sling was tightened and fixed to fascia after one week. This, however, resulted in sling erosion to urethra. Tension was required because of scar tissue from previous operations.

The primary early result was good in 9 out of 13 patients $(69 \%)$. Eight patients were completely dry and one had minor incontinence episodes only if the bladder got overfilled. During follow-up more patients started to leak especially if the bladder got overfilled. At 6 months 5 out of 13 patients (38\%) were still considered to have a good result. After 12 months follow-up all evaluated 11 patients had some degree of incontinence. However, 9 out of 11 pa- tients reported that their incontinence was of lesser degree than before the operation. In urodynamic studies there was a significant increase in bladder volumes and maximal urethral closing pressures postoperatively.

In one patient with increasing postoperative leaks a significant increase in detrusor overactivity could be seen in urodynamic studies. Botulinum toxinA treatment in addition to anticholinergic medication has been attempted in this patient as well as in other patient with lesser degree of overactivity. The first patient has had benefit over a year, but the second patient got a continence for only two months. The increase in bladder pressures is a well-recorded phenomenon that is often detected after bladder outlet surgery (12). It has also been reported previously that the sling procedure results are better in augmented patients (10). Urinary leaking may protect upper urinary tract if detrusor overactivity increases postoperatively. In the present patients none developed upper tract dilatation. Another possible reason for in- 
crease in leaking patients during the follow-up is that the sling material may not be durable. In the patient with sling erosion to urethra, the remnants of the sling inside the urethra had disappeared completely 3 months postoperatively. The increase of incontinence rate after 6 months follow-up also suggests that the durability of the sling material is poor. The durability of the cross-linked porcine dermis grafts has also been questioned previously (13). The non-fixation technique of the sling used in this study may also have an adverse effect on the results. On the other hand it is very unlikely that the sling might loosen after first few weeks.

The operation itself was easily performed in both boys and girls. The only operative difficulties occurred in the two boys who had been operated previously for bladder exstrophy. Both had wide pubic symphysis and scar tissue in the operative area. One of these two patients required excess tension in the sling to achieve sufficient increase in the outflow resistance. However, this resulted in sling erosion. The other required two slings simultaneously to achieve high enough leak point pressure. In one female the insertion needle perforated the bladder. After correction of the position of the insertion needle the operation was completed with no adverse postoperative effects. In our series only one patient had a continent stoma. The others were performing CIC transurethrally. However, all the patients were warned preoperatively that a continent stoma might be required afterwards. None of the patients required continent urinary diversion later on, although one male had temporary problems with CIC during the first months postoperatively.

\section{CONCLUSIONS}

Pelvilace ${ }^{\mathrm{TM}}$ sling is easy to insert in both boys and girls with stress urinary incontinence and with normal pelvic anatomy. Although the primary results were encouraging in the neuropathic patients the outcome appears to worsen already between 1 and 6 months postoperatively. This may be attributed to poor durability of the sling material. At one-year follow-up the results appear to be unacceptably poor despite some degree of subjective improvement.

\section{CONFLICT OF INTEREST}

\author{
None declared.
}

\section{REFERENCES}

1. Kassardjian ZG: Sling procedures for urinary incontinence in women. BJU Int. 2004; 93: 665-70.

2. Cole EE, Adams MC, Brock JW 3rd, Pope JC 4th: Outcome of continence procedures in the pediatric patient: a single institutional experience. J Urol. 2003; 170: 560-3; discussion 563.

3. Bugg CE Jr, Joseph DB: Bladder neck cinch for pediatric neurogenic outlet deficiency. J Urol. 2003;170: 15013; discussion 1503-4.

4. Bent AE, Ostergard DR, Zwick-Zaffuto M: Tissue reaction to expanded polytetrafluoroethylene suburethral sling for urinary incontinence: clinical and histologic study. Am J Obstet Gynecol. 1993; 169: 1198204.

5. Arunkalaivanan AS, Barrington JW: Randomized trial of porcine dermal sling (Pelvicol implant) vs. tensionfree vaginal tape (TVT) in the surgical treatment of stress incontinence: a questionnaire-based study. Int Urogynecol J Pelvic Floor Dysfunct. 2003; 14: 17-23; discussion 21-2.

6. Nilsson CG, Falconer C, Rezapour M: Seven-year follow-up of the tension-free vaginal tape procedure for treatment of urinary incontinence. Obstet Gynecol. 2004; 104: 1259-62.

7. Kuuva N, Nilsson CG: A nationwide analysis of complications associated with the tension-free vaginal tape (TVT) procedure. Acta Obstet Gynecol Scand. 2002; 81:72-7.

8. Dikranian AH, Chang JH, Rhee EY, Aboseif SR: The male perineal sling: comparison of sling materials. $\mathrm{J}$ Urol. 2004; 172: 608-10.

9. Austin PF, Westney OL, Leng WW, McGuire EJ, Ritchey ML: Advantages of rectus fascial slings for urinary incontinence in children with neuropathic bladders. J Urol. 2001; 165: 2369-71; discussion 23712.

10. Perez LM, Smith EA, Broecker BH, Massad CA, Parrott TS, Woodard JR: Outcome of sling cystourethropexy in the pediatric population: a critical review. J Urol. 1996; 156: 642-6.

11. Colvert JR 3rd, Kropp BP, Cheng EY, Pope JC 4th, Brock JW 3rd, Adams MC, et al.: The use of small intestinal 
submucosa as an off-the-shelf urethral sling material for pediatric urinary incontinence. J Urol. 2002; 168: 1872-5; discussion 1875-6.

12. Lopez Pereira P, Somoza I, Martinez Urrutia MJ, Romera L, Jaureguizar E: Can urodynamic studies predict bladder behaviour. J Ped Urol. 2005; 1: 397-401.
13. Gandhi S, Kubba LM, Abramov Y, Botros SM, Goldberg RP, Victor TA, et al.: Histopathologic changes of porcine dermis xenografts for transvaginal suburethral slings. Am J Obstet Gynecol. 2005; 192: 1643-8.

Accepted after revision:

April 4, 2007

\author{
Correspondence address: \\ Dr. Seppo Taskinen \\ Hospital for Children and Adolescents \\ University of Helsinki \\ Stenbäckinkatu 11 \\ 00290 Helsinki, Finland \\ Fax. + 35894717-5314 \\ E-mail: seppo.taskinen@hus.fi
}

\section{EDITORIAL COMMENT}

Currently, there is no consensus regarding which treatment is best adapted for urinary incontinence of neurogenic bladders. Therefore, it remains challenging to treat this pathology both medically and surgically. The risk of rapid degradation of the upper urinary tract requires close monitoring of these patients in order to offer possible treatment options. Degradation of renal function and incontinence can be greatly improved by clean intermittent self catheterization and pharmacological therapy. Nevertheless, many patients experience persistent leakage. The mechanism of incontinence can result either from a low bladder capacity or low compliance, non inhibited detrusor activity or from sphincteric deficiency. Numerous procedures have been proposed to increase bladder outlet resistance particularly in children with neurogenic bladder dysfunction. The therapeutic choices aim to achieve an equilibrium between urethral and bladder strength and protection of the upper urinary tract as well as urethral resistance and bladder compliance.
In cases of urinary incontinence due to neurogenic bladders, the therapeutic choices are based on the analysis of several parameters. The first is the clinical picture, including the severity of incontinence, dysuria and urgency. The second parameter is urodynamics for patient assessment, with data on bladder compliance, detrusor hyperactivity, dyssynergia, and urethral pressure. Moreover, in Europe the leak point pressure is often used to evaluate female urge incontinence, however, it is not a standard procedure in children for urodynamic evaluation. Another parameter is the patient's functional independence, including the aptitude for voiding and catheterization. The final parameter is the degree of understanding and acceptance of patient re-education and monitoring, as well as the daily routine environment of the patient.

Several techniques are currently available to increase urethral resistance in children with neurogenic bladder. Injections of bulking agents are one technique; however, this approach is not recommended for 
treating sphincteric insufficiency in the myelodysplastic pediatric population (1-3). Urethral lengthening, i.e. Kropp's procedure provides good but inconstant results in terms of continence, however catheterization can be difficult particularly in male patients $(4,5)$. Moreover, modifications described by Pippi Salle in order to improve catheterization problems have resulted in reduced continence (6). Artificial sphincters can be complicated by an urethral erosion when associated catheterization is required for voiding as in the case of many patients with spinal dysraphism $(7,8)$. The outcome complication of erosion and problems with catheterization suggest that this approach is not recommended when the urethra is catheterized.

Furthermore, rectus fascial slings have been reported to provide continence in $50 \%$ to $93 \%$ of cases (9-12). In contrast, it is known that myelodysplastic children frequently have a poor nutritional status or have undergone prior abdominal procedures responsible for deficient and unusable fascia.

Taskinen et al. performed TVT minimally invasive procedure with porcine dermis acellular collagen matrix (Pelvilace ${ }^{\mathrm{TM}}$, Bard Medical). Several authors have reported slings using collagen-based biomaterials, which have shown efficacy for urinary stress incontinence. However, there is a wide variability in terms of collagen content consistency and subsequently therefore in clinical results (13-15). At our institution, in treating female urinary incontinence, the transobturator tape (TOT) procedure is preferred as it provides less postoperative retention rate and fewer per and postoperative complications (16). The absence of need to retropubic space puncture significantly limits the risk of severe complications such as those reported with TVT, bowel and iliac vessel, injuries. Therefore, the large veins of the Santorini's plexus are avoided. Minimally invasive TVT procedure is in fact no longer used in our department.

Moreover, the above mentioned authors used the leak point pressure (LLP) possibly as a predictor of good results, as it has been shown that LLP is helpful in the diagnosis of urinary incontinence. Nevertheless, it appears to be of minimal benefit in predicting the outcome of the mini-invasive TVT procedure (17).
In cases of urinary incontinence due to neurogenic bladder, we recently reported our results on the bladder wall wraparound procedure in association with a bladder augmentation. This procedure provides good results for continence in association with a bladder augmentation particularly in women (18).

In conclusion, the main problem in comparing studies reported in the literature remains the definition of continence and the definition of success rates. In fact, many authors have included "improved" cases as successes. Urinary incontinence due to neurogenic bladder remains challenging to treat patients medically and surgically. However, this must be performed in specialized centers.

\section{ACKNOWLEDGMENT}

Richard Medeiros, Rouen University Hospital Editor and Philippe Grise Professor of Urology helped in editorial assistance.

\section{REFERENCES}

1. Kassouf W, Capolicchio G, Berardinucci G, Corcos J: Collagen injection for treatment of urinary incontinence in children. J Urol. 2001; 165: 1666-8.

2. Guys JM, Fakhro A, Louis-Borrione C, Prost J, Hautier A: Endoscopic treatment of urinary incontinence: longterm evaluation of the results. J Urol. 2001; 165: 2389-91.

3. Godbole P, Bryant R, MacKinnon AE, Roberts JP: Endourethral injection of bulking agents for urinary incontinence in children. BJU Int. 2003; 91: 536-9.

4. Kropp KA, Angwafo FF: Urethral lengthening and reimplantation for neurogenic incontinence in children. J Urol. 1986; 135: 533-6.

5. Snodgrass W: A simplified Kropp procedure for incontinence. J Urol. 1997; 158: 1049-52.

6. Salle JL, McLorie GA, Bagli DJ, Khouri AE: Urethral lengthening with anterior bladder wall flap (Pippi Salle procedure): modifications and extended indications of the technique. J Urol. 1997; 158: 585-90.

7. Kryger JV, Gonzalez R, Barthold JS: Surgical management of urinary incontinence in children with neurogenic sphincteric incompetence. J Urol. 2000; 163: 256-63. 
8. Levesque PE, Bauer SB, Atala A, Zurakowski D, Colodny A, Peters C, et al.: Ten-year experience with the artificial urinary sphincter in children. J Urol. 1996; 156: 625-8.

9. Elder JS: Periurethral and puboprostatic sling repair for incontinence in patients with myelodysplasia. J Urol. 1990, 144: 434-7.

10. Castellan M, Gosalbez R, Labbie A, Ibrahim E, Disandro $\mathrm{M}$ : Bladder neck sling for treatment of neurogenic incontinence in children with augmentation cystoplasty: long-term followup. J Urol. 2005; 173: 2128-31.

11. Bugg CE Jr, Joseph DB: Bladder neck cinch for pediatric neurogenic outlet deficiency. J Urol. 2003; 170: 1501-3.

12. Walker RD, Erhard M, Starling J: Long-term evaluation of rectus fascial wrap in patients with spina bifida. $\mathrm{J}$ Urol. 2000; 164: 485-6.

13. Colvert JR 3rd, Kropp BP, Cheng EY, Pope JC, Brock JW, Adams MC, et al.: The use of small intestinal submucosa as an off-the-shelf urethral sling material for pediatric urinary incontinence. J Urol. 2002; 168: $1872-5$.
14. Misseri R, Cain MP, Casale AJ, Kaefer M, Meldrum KK, Rink RC: Small intestinal submucosa bladder neck slings for incontinence associated with neuropathic bladder. J Urol. 2005; 174: 1680-2.

15. Grise P: [The future of biomaterials in urology]. Prog Urol. 2002; 12: 1305-9. French

16. Grise P, Droupy S, Saussine C, Ballanger P, Monneins F, Hermieu JF, et al.: Transobturator tape sling for female stress incontinence with polypropylene tape and outside-in procedure: prospective study with 1 year of minimal follow-up and review of transobturator tape sling. Urology. 2006; 68: 759-63.

17. Rodriguez LV, de Almeida F, Dorey F, Raz S: Does Valsalva leak point pressure predict outcome after the distal urethral polypropylene sling? Role of urodynamics in the sling era. J Urol. 2004; 172: 2104.

18. Albouy B, Grise P, Sambuis C, Pfister C, Mitrofanoff P, Liard A: Pediatric urinary incontinence: evaluation of bladder wall wraparound sling procedure. J Urol. 2007; 177: 716-9.

Dr. Baptiste Albouy Department of Urology, Rouen University Hospital Rouen, France E-mail: baptistealbouy@mac.com

demonstrated the efficacy of TVT or TOT in female stress incontinence with a long term success rate ranging between $70-80 \%$. These results are significantly better when stress rather than mixed incontinence was the preoperative situation and when the incontinence grade was mild or moderate. Therefore, in my opinion, some of the reasons for the unsatisfactory continence rate results in this study were that urinary incontinence in neuropathic bladders or exstrophy patients is more complex than simple stress incontinence because, most of the time, incontinence has mixed causes. Moreover, the cause of incontinence in these patients is more functional than 
anatomical and the incontinence is severe in many cases. We could speculate that these poor long-term continence results could be improved by selecting these patients in a more appropriate way. Most exstrophy patients have had prior bladder neck surgery with scar tissue around it and this increases the risk of sling erosion and worsens the continence results after a sling procedure. Therefore, in these patients the sling is not a good option to improve continence. One could improve the continence results with this procedure in neuropathic patients only in those with a mild or moderate incontinence who have a bladder with good com- pliance and low pressure. However, unfortunately this kind of neuropathic patient is not frequent. In these patients that are amenable to a sling procedure, it might be better to use more durable or even synthetic materials and to tighten the sling.

\section{REFERENCE}

1. Porena M, Costantini E, Frea B, et al.: Tension-free vaginal tape versus transobturator tape as surgery for stress urinary incontinence: Results of a multicentre randomised trial. European Urology (in press).

Dr. Lopes Pereira

University Hospital La Paz

Unidad de Urologia Infantil

Madrid, Spain

E-mail:plpuro@hotmail.com

\section{EDITORIAL COMMENT}

The treatment of urinary incontinence in children due to insufficient urethral resistance is challenging. There are two groups in the pediatric population in whom an incompetent sphincter could cause urinary incontinence. In children with myelodysplasia urinary incontinence is related to an incompetent sphincter alone in only a few patients. Most cases are associated with an overactive detrusor. In the group of patients with bladder exstrophy, continence can be achieved by a bladder neck procedure, which creates an outlet obstruction. Patients with incontinence after a bladder neck procedure represent one of the most challenging groups in pediatric urology. These patients need an operation with a high success rate, because incontinence in older children and adolescence is associated with severe social and psychological problems for the patient and their relatives.
This is an honest report on results using an artificial sling (Pelvilace ${ }^{\mathrm{TM}}$ from Bard medical). It includes 13 patients; most were older children and/or young adults (median age 15.5 years, range 8.9 27.5). The sling was implanted due to sphincteric incompetence in 8 patients with myelodyplasia, one had a tethered chord and 4 patients belong to the group with bladder-exstrophy-epispadias complex. Shortly after the procedure 8 of the 13 patients were dry. However, after 12 months none of the 11 patients with follow-up were dry. In one patient the sling eroded the urethra.

In patients with a neurogenic bladder and sphincteric incompetence, a low pressure bladder or reservoir is mandatory before an outlet procedure can be performed. Even if there is no hyperactive bladder previous to the procedure, after increasing the outlet 
resistance hyperactivity can occur. It is important to understand the natural history of myelodysplasia. The neurology changes over time (deterioration of the hydrocephalus, hydromyelia, the Arnold-Chiari malformation, tethering of the spinal cord and/or the nerve roots and so on). It is a dynamic process needing close monitoring, because these children have a risk for future upper tract deterioration.

After conservative management, the surgical options depend on the neurological and mental status of the patient. It is absolute mandatory that these patients are able to perform a clean intermitent catheterization (CIC) before any procedure is performed to achieve continence. Compliance is another point. These patients have to do CIC on a regular basis. If the patient is not able to perform a CIC or is non-compliant, an incontinent diversion may be the better solution. If the patient depends on other people to perform the CIC, she or he has no benefit from a continence procedure. A colonic or ileal conduit seems to be the better solution for these patients instead of living with diapers. The colonic conduit has especially proven to be a safe procedure in the long run (1).

Those who are compliant and are able to perform a CIC have a couple of surgical options. If these patients are able to perform a CIC via the urethra, a facial sling plasty or a bladder neck procedure can be performed. However, this is not possible in obese patients and sometimes after orthopedic surgery at the spine, because they can not reach the meatus. For the fascial sling the continence rate is between 40$100 \%$ with a revision rate of $15 \%$ (2). Bladder neck reconstruction using the Salle or Kropp technique is much more complicated and continence can be expected in $50-81 \%$ of the patients (2). If the patient really wants to become dry and has good compliance, bladder neck closure together with a continent cutaneous stoma would be the next step. In cases with a small non-compliant bladder continent cutaneous diversion should be considered. Particularly in those patients in whom reimplantation of the ureters is required, performing a continent diversion may be even easier rather than performing a complicated bladder augmentation, reimplantion of the ureters, bladder neck closure and creation of a cutaneous stoma $(3,4)$, where the complications risks may be even higher. In the older group of patients, an artificial urinary sphincter is a good option if the patient is ambulatory and able to handle the mechanism. The continence rates are between $76-100 \%$ (2), the revision rate could reach $100 \%$ in the long run.

In patients with bladder exstrophy and a suitable bladder plate, primary bladder closure together with genital reconstruction should be the first choice. In patients with an incontinent epispadias with an open bladder neck, reconstruction is recommended. However after failure of primary reconstruction, urinary diversion using the recto-sigmoid pouch or a continent cutaneous diversion should be considered. In this group of patients, who have a low success rate, if the primary procedure fails, a procedure with an acceptable complication rate and a high continence rate is needed (5). The concept of preserving the bladder with multiple operations and ending up with bladder neck closure, bladder augmentation, continent cutaneous stoma, the risk for metabolic complications and secondary tumors is not different to a secondary urinary diversion. However, the number of operations may be less.

Looking at the honest results of the presented series using an artificial sling, this operation should not be used in children. The success rate is not acceptable, even if this is a minimally invasive procedure.

\section{REFERENCE}

1. Stein R, Wiesner C, Beetz R, Schwarz M, Thuroff JW: Urinary diversion in children and adolescents with neurogenic bladder: the Mainz experience Part III: Colonic conduit. Pediatr Nephrol. 2005; 20: 932-6.

2. Kryger JV, Gonzalez R, Barthold JS: Surgical management of urinary incontinence in children with neurogenic sphincteric incompetence. J Urol. 2000; 163: 256-63.

3. Stein R, Wiesner C, Beetz R, Pfitzenmeier J, Schwarz M, Thuroff JW: Urinary diversion in children and adolescents with neurogenic bladder: the Mainz experience Part II: Continent cutaneous diversion using the Mainz pouch I. Pediatr Nephrol. 2005; 926-31.

4. Stein R, Wiesner C, Beetz R, Schwarz M, Thuroff JW: Urinary diversion in children and adolescents with 
neurogenic bladder: the Mainz experience Part I: Bladder augmentation and bladder substitution therapeutic algorisms. Pediatr Nephrol. 2005; 20: 9205.
5. Stein R, Fisch M, Black P, Hohenfellner R: Strategies for reconstruction after unsuccessful or unsatisfactory primary treatment of patients with bladder exstrophy or incontinent epispadias. J Urol. 1999; 161: 1934-41.

Dr. Raimund Stein

Department of Urology

Johannes Gutenberg University

Mainz, Germany

E-mail:Stein@urologie.klinik.uni-mainz.de

\section{EDITORIAL COMMENT}

Pediatric sphincteric incompetence remains a challenge for urologic surgeons. Management options include periurethral injection, bladder neck reconstruction, artificial sphincter placement, or slings. In general injection therapy has been least successful, while the artificial urinary sphincter most successful, but concern the artificial sphincter will need periodic revision throughout life has spurred interest to develop alternatives. Currently in the US patients with exstrophy/epispadias complex typically undergo bladder neck revision by either the YoungDees or Leadbetter-Mitchell approach, whereas children with neuropathic sphincteric incompetence receive slings.

The authors managed patients with exstrophy/ epispadias and neuropathic sphincteric incompetence with slings, testing a minimally invasive approach currently popular in adults with stress urinary incontinence. They used intraoperative leak point pressure measurements to determine when the sling was sufficiently tight. At one month follow-up 9 (69\%) of 13 patients were dramatically improved, but by 1 year most were again requiring multiple pads daily even if the amount of leakage was less than preoperatively. Postoperative urodynamics were obtained at 6 months, but it would have been useful to report subsequent changes in the 5 patients whose pad use increased over the next 6 months to determine if sling support was lost.
Slings for neuropathic incontinence have been placed both loosely or tightly, in a "U" or "X" shape from pubis under the bladder neck and back to pubis, or wrapped $360^{\circ}$ around the bladder neck for compression and support. Several published series show all these techniques effective and durable with follow-up greater than 1 year. Therefore it appears a more invasive surgical procedure may be rewarded with a longer period of improved continence. Another potential advantage to surgery through an abdominal incision is simultaneous creation of an appendicovesicostomy, which may greatly facilitate intermittent catheterization and promote self-care. In my institution we routinely perform a $360^{\circ}$ sling with appendicovesicostomy.

A comment regarding augmentation in children with sphincteric incompetence is also warranted. The authors report 1 patient with simultaneous enterocystoplasty for detrusor pressures of $80 \mathrm{~cm}$ water. However, they did not provide information regarding bladder capacity or response to anticholinergics in this child, nor did they explain why a bladder outlet procedure was needed when such high intravesical pressures could be achieved. Two other patients with exstrophy had prior augmentation before their bladder neck procedure, as did 2 with myelomeningocele. Since it cannot be determined which exstrophy bladders will enlarge when the outlet is enhanced, we perform bladder neck surgery first 
and reserve augmentation for those who do not achieve increased bladder volume over time. Augmentation for neurogenic bladders with low outlet resistance usually will not resolve incontinence, and I personally believe most children undergoing slings do not, and will not, require augmentation if managed with anticholinergic medications in sufficient dosages (1).

The authors are commended for considering a minimally invasive technique and for clearly reporting pad usage both preoperatively and at intervals postoperatively. Loss of initial improvement in most patients and erosion of the sling in another suggest open surgical placement of autologous slings provides more durable results in patients with neuropathic sphincteric incompetence.

\section{REFERENCE}

1. Snodgrass WT, Elmore J, Adams R: Bladder neck sling and appendicovesicostomy without augmentation for neuropathic incontinence in children. J Urol. 2007; 177: 1510-4.

Dr. Warren T. Snodgrass

Dept of Urology, Pediatric Urology Section University of Texas Southwestern Med Ctr \& Children's Med Ctr Dallas Dallas, Texas, USA

E-mail:warren.snodgrass@childrens.com

\section{REPLY BY THE AUTHORS}

In our study, sphincteric incompetence was considered the main reason for urinary incontinence in all patients except the one who had unusually high-level bladder overactivity in spite poor sphincter. The diagnosis of the sphincteric incompetence was based on patient history, leak point pressures and urethral pressure profile measurements. The extrophy patients had had previously Young-Dees operation to the bladder neck without adequate success. Previously we have had some success with injectable debulking agents in neurogenic patients and sometimes in nonneurogenic patients. Because according to our experience even a slight increase in outlet resistance may lead to continence in some of these difficult patients, we decided to attempt mini-invasive collagen sling in a hope that it would be slightly more efficient and stabile than a debulking agent. The primary results were satisfactory, but unfortunately, the result was not long lasting. Undoubtedly synthetic sling materials would produce better long lasting results. However, in a growing child the use of synthetic material would lead to erosion and also in full grown patients the erosion rate would probably be higher than in a traditional tension free technique, because in these patients some tension is needed. It seems, that autologous fascia is best material at this moment, if a sling operation is attempted in these patients. 